\title{
Anesthetist Perception of Anesthetist-Surgeon Conflicts in Operation Theater
}

ARSHI NAZ ${ }^{1}$, VIJAI KUMAR ${ }^{1}$, MIRZA SHAHZAD BAIG ${ }^{1}$, SIDRA JAVED ${ }^{1}$, SAMITA S KHAN ${ }^{1}$, BASMA SALMAN ${ }^{1}$

${ }^{1}$ MBBS, FCPS Consultant Department of Anesthesia, Shaheed Mohtarma Benazir Bhutto Institute of Trauma, Karachi

Corresponding author: Dr. Arshi Naz, Email: nazarshi33@gmail.com, Cell No.+923119944962

\begin{abstract}
Objective: The aim of this study is to determine the anesthetist perception of anesthetist-surgeon conflicts in Operation Theater.

Study Design: Cross-sectional

Place and Duration: Study was conducted at department of Anesthesia, Shaheed Mohtarma Benazir Bhutto Institute of Trauma, Karachi for duration from $1^{\text {st }}$ July 2020 to $1^{\text {st }}$ June 2021.

Methods: Total 50 anesthesiologists of both genders were presented in this study. Participants were aged between 25-55 years. Details demographics including age, sex, working experience and marital status were recorded after taking informed consent. Reasons of conflicts (lack of team work) among surgeons and anesthetics were observed due to this patients work affected. Complete data was analyzed by SPSS 20.0 version.

Results: Mean age of anesthesiologists was 37.68 6.81 years. $30(60 \%)$ were males among and $20(40 \%)$ were females. $40(80 \%)$ anesthetics were married. Working relationships disturbed in anesthetics were $35(70 \%)$. Patient pressure on surgeons, lack of consideration of anesthesiologist instructions, patient ignorance of anesthesiologists' roles, lack of information about the patients' needs, decisions regarding the urgency of operations, the lack of coordination in departments regarding operational priorities, the lack of an out-patient anesthesia clinic and finally shortage of work facilities were the predictors of conflicts among anesthesiologist.

Conclusion: We have found a number of reasons that participants believe to trigger conflict. Attention to these questions may assist harmonize surgeons' workplace with anesthesiologists.

Keywords: Anesthesiologist, Conflicts, Operating room
\end{abstract}

\section{INTRODUCTION}

The OT setting is the most complex and turbulent location of work where two coequal doctors share one patient obligation. Anesthetic has in the past been recognized as an after-scenes specialty, where a surgeon who administers anesthesia was regarded as one of the surgeons. Large developments in anesthesia shifted the anesthesiologist's status incrementally from an assistant to an independent specialist. This transformation called for respect and recognition of knowledge and abilities of each other. In the underdeveloped countries, the general population does not recognize the role of an anesthetist in the success of the surgery. In addition, the surgeon is considered as the primary doctor and anesthesiologist as a consultant who will take part in a patient's peri-operative treatment, even from a professional point of view. Failure to recognize the role of an anesthesiologists both within and outside of the OR, a lack of appreciation by the surgeon and poor social connection with the patient reduce an anesthesiologist's self-esteem. In high- pressure environments, conflicting conflicts can range from minor discrepancies to personality clashes, sometimes physical confrontations[3]. Paintery quality depends on effective team work for which multidisciplinary work is necessary. Distinctiveness, opinion or values, experience and interests between a surgeon and an anesthesiologist can arise when working in high pressure environment. [6]

There is no more critical relationship than the OR surgeon and anesthesiologist. In high-pressures workplaces like operating rooms, when two highly educated and experienced physicians work together, discord is common since each person's own thinking, values and beliefs differ and reacts in differing situations, this may lead to conflict.[7] Studies have shown that at least $20 \%$ of the executive's life is in conflict.

Behind the scene specialist, anesthesiology has long been considered. Patients regard surgeons as their primary care practitioners, and know little about anesthetist's role in the OR. The merits of preoperative evaluation aimed at reducing anesthetic and surgical risk are not recognized by patients. You fail to follow directions from the anesthesiologist and assign your surgeon their overall safety and well-being[8]. A study was undertaken on the function of anesthesiologist in the treatment of patients and assessing the knowledge of paramedical staff. It was really disappointing to find that just $49.20 \%$ of the employees know that anesthesia is a different subject and $60 \%$ of them know that it is a definite part of the OR. 35.85 percent of anesthetic scientists thought surgeon and rest assistants have no clue what the anestheticist does.[9] This reduces self-esteem, especially as much effort is needed to gain this skill. The patient's lack of appreciation for his/her position in OR and lack of compliance with their instructions causes frustration and leads to conflict between the surgeon and the anesthesiologist.

In this paper we examine the different sources of conflict, resolve and avoid conflicts between surgeons and anesthesiologists and preserve healthy working relations in RAs since everyone has a right to be treated with dignity and respect in the workplace.

\section{MATERIAL AND METHODS}

This cross-sectional study was conducted atdepartment of Anesthesia, Shaheed Mohtarma Benazir Bhutto Institute of Trauma, Karachi for duration from $1^{\text {st }}$ July 2020 to $1^{\text {st }}$ June 2021 and comprised of 50 participants. Participants' 
detailed demographics including age, sex and marital status were recorded after taking informed written consent.

Participants were aged between 25-55 years. Details demographics of participants age, sex and marital status were recorded in the predesigned proforma. Reasons of conflicts (lack of team work) among surgeons and anesthetics were observed due to this patients work affected. Complete data was analyzed by SPSS 20.0 version. Categorical variables were assessed by percentages and frequencies.

\section{RESULTS}

Mean age of anesthesiologists was $37.68 \pm 6.81$ years. 30 $(60 \%)$ were males among and $20(40 \%)$ were females. 40 $(80 \%)$ anesthetics were married. (Table 1)

Working relationships disturbed among anesthetics were 35 (70\%). (Table 2)

Table 1: Baseline details demographics of enrolled cases

\begin{tabular}{|l|l|l|}
\hline Variables & Frequency No. & $\%$ \%age \\
\hline Mean age & $37.68 \pm 6.81$ & - \\
\hline Working Experience & \multicolumn{2}{|l|}{} \\
\hline$<5$ years & 15 & \\
\hline$>5$ years & 35 & 30 \\
\hline Gender & 30 & 70 \\
\hline Male & 20 & 60 \\
\hline Female & \multicolumn{2}{|l|}{} \\
\hline Marital status & 40 & 80 \\
\hline Married & 10 & 20 \\
\hline Unmarried &
\end{tabular}

Table 2: Comparison of working relationships disturbed among anesthetics

\begin{tabular}{|l|l|l|}
\hline Working relationship & Frequency No. & \%age \\
\hline Disturbed & 35 & 70 \\
\hline Yes & 15 & 30 \\
\hline No &
\end{tabular}

Table 3: Causes of conflicts among anesthetics in OT

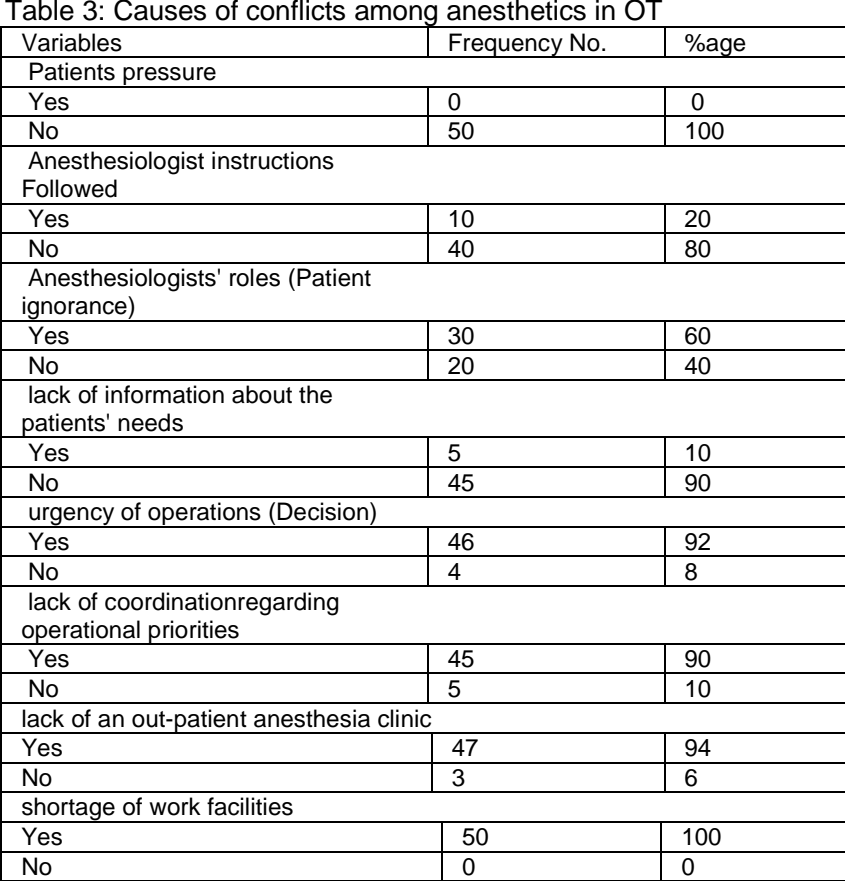

Patient pressure on surgeons, lack of consideration of anesthesiologist instructions, patient ignorance of anesthesiologists' roles, lack of information about the patients' needs, decisions regarding the urgency of operations, the lack of coordination in departments regarding operational priorities, the lack of an out-patient anesthesia clinic and finally shortage of work facilities were the predictors of conflicts between surgeons and anesthesiologists. (Table 3)

\section{DISCUSSION}

In the current healthcare environment, it is important for all stakeholders within a facility to work as a team for optimal efficiency. No relationship is more crucial than that of a surgeon and an anesthesiologist. In our study 50 surgeons and 50 anesthetics were presented. Mean age of anesthesiologists were $34.68 \pm 7.81$ years with mean BMI $25.48 \pm 4.43 \mathrm{~kg} / \mathrm{m}^{2} .20$ (40\%) were among anesthetics were females. These findings were comparable to the previous study.[10,11]

In this cross-sectional study we discovered that anesthesiologists' troubling behavior (about $84 \%$ ) considers that the interactions with their surgeons are disturbed and conflicts exist. Conflicts have been considered to be the most difficult and stressful aspects of their work in the perspective of many anesthesiologists. Conflicts have been identified as the most difficult and stressful aspects of their work by many anesthesiologists. Conflicts in operating rooms can prevent safe and effective anesthetic care, but the resolution of conflicts is a significant factor in collaboration and is essential to good treatment for the patient.[12]

In the last study Personal issues such poor communication, attitude, differences in values and opinions were reported to have had more frequent effects on workplace relationships by anesthesiologists than by surgeons. The main reasons of conflict have been determined to be poor social connection outside work and the lack of appreciation of doctors. Characteristics often found among surgeons and anesthesiologists, such as perfectionism and compulsiveness, can make it harder for such doctors to recognize and control other people's skill. [13] Other physicians generally saw surgeons as dominant, cold, impersonal, impatient, aggressive, authoritarian, arrogant, prestigious, and self-centered[14], which may spark conflict in a number of respects in negative terms. Others, however, stressed that poor communication is one of the most typical factors leading to conflict amongst employees. [15]

In the present study, patient pressure on surgeons, lack of consideration of anesthesiologist instructions, patient ignorance of anesthesiologists' roles, lack of information about the patients' needs, decisions regarding the urgency of operations, the lack of coordination in departments regarding operational priorities, the lack of an out-patient anesthesia clinic and finally shortage of work facilities were the predictors of conflicts between surgeons and anesthesiologists. These were comparable to the previous some studies. $[10,16]$

The absence of an anesthetic clinic was recognized as a common source of conflict anesthesiology. Preoperative anesthetic clinics have been reported to help 
patients' before to surgery to maximize their condition.[19] Patient safety and content have also improved [17], preoperative medical consultation resources, laboratory research[20], and hospital stay[21] have been reduced. Furthermore, the preoperative visit to a patient's anesthesia clinic showed that cancellation of the surgical room decreased [22].

Finally, various reasons have been discovered in this study, which are seen as substantial contributions to disagreements and disrupted working relations among surgeons and anesthesiologists. Some of the explanations for both groups, such as lack of interpersonal skills, lack of personnel and overwork, were same. Conflicts and poor working relationships of surgeon-anesthesiologists are worldwide and can influence the productivity and attitude of physicians.

\section{CONCLUSION}

We have found a number of reasons that participants believe to trigger conflict. Attention to these questions may assist harmonize surgeons' workplace with anesthesiologists.

\section{REFERENCE}

1. Studdert DM, Mello MM, Burns JP, Puopolo AL, Galper BZ, Truog RD, et al. Conflict in the care of patients with prolonged stay in the ICU: Types, sources, and predictors. Intensive Care Med. 2003;29:1489-97.

2. Jackson SH. The role of stress in anaesthetists' health and well-being. ActaAnaesthesiol Scand. 1999;43:583-602

3. Katz JD. Conflict and its resolution in the operating room. J ClinAnesth. 2007;19:152-8.

4. Gillespie BM, Kermode S. How do perioperative nurses cope with stress? Contemp Nurse. 2003;16:20-9

5. Schaefer HG, Helmreich RL, Scheidegger D. Safety in the operating theatre - Part 1: Interpersonal relationships and team performance. CurrAnaesthCrit Care. 1995;6:48-53

6. El-Masry R, Shams T, Al-Wadani H. Anesthesiologist Surgeon conflicts at workplace: An exploratory single Center study from Egypt. Ibnosina $J$ Med Biomed Sci. 2013;5:148-56

7. Lipcamon JD, Mainwaring BA. Conflict resolution in healthcare management. Radiol Manage. 2004;26:48-51

8. Kirschbaum K. Physician communication in the operating room: Expanding application of face-negotiation theory to the health communication context. Health Commun. 2012;27:292-301
9. Bhattarai B, Kandel S, Adhikari N. Perception about the role of anesthesia and anesthesiologist among the paramedical staffs: Perspective from a medical college in Nepal. Kathmandu Univ Med J (KUMJ) 2012;10:51-4

10. Ragaa El-Masry1, Tarek Shams2, Hamed Al-Wadani3. Anesthesiologist-Surgeon Conflicts at the Workplace: An Exploratory Single-Center Study from Egypt. Ibnosina J Med BS 2013,5(3)

11. Attri JP, Sandhu GK, Mohan B, Bala N, Sandhu KS, Bansal L. Conflicts in operating room: Focus on causes and resolution. Saudi J Anaesth. 2015;9(4):457-463.

12. Katz JD. Conflict and its resolution in the operating room. Journal of Clinical Anesthesia 2007;19:152-8

13. Thomas EJ, Sexton JB, Helmreich RL. Discrepant attitudes about teamwork among critical care nurses and physicians. Crit Care Med 2003;31:956-9

14. Mitra S, Sinha PK, Gombar KK, Basu D. Comparison of temperament and character profiles of anesthesiologists and surgeons: a preliminary study. Indian $J$ Med Sci 2003;57(10):431-6

15. Studdert DM, Mello MM, Burns JP, Puopolo AL, Galper BZ, Truog RD, Brennan TA. Conflict in the care of patients with prolonged stay in the ICU: types, sources, and predictors. Intensive Care Med 2003;29:1489-97

16. Kirschbaum K. Physician communication in the operating room: expanding application of facenegotiation theory to the health communication context. Health Commun 2012;27(3):292-301

17. Parsa P, Sweitzer B, Small SD. The contribution of a preoperative evaluation to patient safety in highrisk surgical patients: a pilot study. AnesthAnalg 2004;100:S147.

18. 18. Hepner DL, Bader AM, Hurwitz S, Gustafson M, Tsen LC. Patient satisfaction with preoperative assessment in a preoperative assessment testing clinic. AnesthAnalg 2004;98:1099-105.

19. 19. Kopp VJ. Preoperative preparation: value, perspective and practice in patient care. AnesthesiolClin North Am 2000;18:551-74.

20. 20. Parker BM, Tetzlaff JE, Litaker DL, Maurer WG: Redefining the preoperative evaluation process and the role of the anesthesiologist. J ClinAnesth 2000;12:350- 6 .

21. 21. Halaszynski TM, Juda R, Silverman DG. Optimizing postoperative outcomes with efficient preoperative assessment and management. Crit Care Med 2004;32(suppl):S76-86.

22. 22. Ferschl M, Tung A, Sweitzer B, Huo D, Glick D: Preoperative clinic visits reduce operating room cancellations and delays. Anesthesiology 2005;103:855-9. 